\title{
Intelligent Work: Person Centered Operations, Worker Wellness \& the Triple Bottom Line
}

\author{
Joan Cahill ${ }^{10000-0001-6944-744 X]}$, Vivienne Howard ${ }^{1}$, Yufei Huang ${ }^{2}$, Junchi Ye, Stephen \\ Ralph $^{3}$, Aidan Dillon ${ }^{3}$ \\ ${ }^{1}$ School of Psychology, Trinity College Dublin, Dublin, Ireland \\ ${ }^{2}$ Trinity School of Business, Trinity College Dublin, Dublin, Ireland \\ ${ }^{3}$ Zarion Ltd. \\ cahilljo@tcd.ie
}

\begin{abstract}
.
Work has an important role in terms of promoting wellbeing. However, it can also have negative effects on our physical and mental wellbeing leading to stress, fatigue, poor teamwork and engagement, and burnout. Many companies treat workers in terms of enterprise resources. Operations management often overlooks the 'human factor' and specifically, the relationship between worker wellbeing and performance, and the design of work management processes and associated technologies to support this. The impact of new work and workforce practices/trends such as the blended and flexible workforce along with new automation and artificial intelligence (AI) technologies enabling business process, performance/work, and workforce management, presents both risks and opportunities. This paper introduces a new work management concept - namely, 'intelligent work'. Intelligent work is defined in relation to work that is smart, health, ethical and safe. Critically, it is underpinned by concepts of workplace health protection and promotion, along with progress in automation and AI technologies. This concept has been advanced a part of a human factors action research program addressing responsible business, sponsored by the Irish government.
\end{abstract}

Keywords: The Future of Work, Intelligent Work, Healthy Work, Triple Bottom Line, Health Promotion, Health Protection, Operations Management, Human Factors, Ethics, Sustainable People Centered Operations, Financial Services

\section{Introduction}

Operations management practices focus heavily on metrics such as productivity, efficiency, and customer experience. This has consequences for individuals (i.e., employee wellness and health impact) and for society. As stated by Elkington (2019), human activity should not compromise the long-term balance between the economic, social, and environmental pillars [1]. Many Fortune 500 companies have embraced concepts of 'responsible business' [2]. However, as argued by the International Labor Organisation 
(ILO) [3] and the Tripartite Labor Coalition [4], organizations must act on their responsibilities to their workforce too.

Financial institutions are utilizing new automation, artificial intelligence (AI) and machine learning (ML) technologies to better manage their business processes, their workforce, and customer relationships. Such technologies are changing how work is managed and delivered, and the human role in the system. Workers have concerns about how these technologies will change their job status, their role, and their experience of work. Further, the movement to remote work arising from the COVID 19 pandemic has highlighted the need to address the human and ethical issues surrounding both remote work and technology mediated work supervision. In addition, worker expectations of 'work' and the home/work interface have changed. Specifically, Millennial and Generation $\mathrm{Z}$ employees are looking for more autonomy and flexibility in work.

This paper reports on a new concept for work management and monitoring - Intelligent Work (IW). First, a background to this concept is provided. The methodological approach underpinning the specification of this concept is then introduced. The findings are then presented. A short overview of the emerging IW concept is outlined. The concept is then discussed, and some conclusions drawn.

\section{Background}

Financial Services (FS) refers to professional services involving the investment, lending, and management of money and assets. Work is serviced and managed by finite teams to provides value to the company and its customers. This work can be classified into two types - transactional work and knowledge work. Transactional work involves the processing of information related to a particular transaction or work item. Knowledge work denotes any activity involving the application of existing knowledge to current problems, the use of knowledge within production processes and the creation of new knowledge.

Operations management refers to the ways in which a business manages the resources (i.e., people, materials, technologies) responsible for delivering work. This spans the production lifecycle including planning, organizing, and supervising work. Lean methods emphasize productivity/efficiency and effectiveness [5]. More recently, people centered operations methods are being deployed. These methods recognize the important contribution of work to a person's wellbeing.

Most financial institutions utilize technology to manage their business processes, their workforce, and customer relationships. These technologies are shaping both work and the role of the human in the system. Increasingly, transactional work is undertaken by robotic agents (i.e., robotic process automation technologies). Other kinds of technologies are deployed for the management of work. This includes business process management (BPM) technologies, digital process automation (DPA) technologies and dynamic case management (DCM) technologies.

As stated by the Centers for Disease Control and Prevention (CDC), the workplace is an important setting for health protection, health promotion and disease prevention programs [6]. The World Health Organisation (WHO) propose a model of 'healthy 
work' and a 'healthy workplace' in which both physical and psychosocial risks are managed [7]. Critically, a healthy workplace is defined 'as one in which workers and managers collaborate to use a continual improvement process to protect and promote the health, safety and well-being of all workers, and the sustainability of the workplace' [7]. The management of psycho-social risk is also emphasized in the new international standards on psychological health in work [8] and safe work during the COVID 19 Pandemic [9].

As proposed in the 'Job Strain Model' [10], employees whose jobs involve high demands and low decision latitude experience the highest levels of work-related stress (WRS). Studies in the information systems literature have found that individuals who experience technostress have lower productivity and job satisfaction, and decreased organization commitment [11]. A 2015 study by Barber and Santuzzi introduced the construct of workplace 'tele-pressure' [12]. This represents the combination of both preoccupation and urge to immediately respond to work-related messages (for example, emails). Such behavior to be associated with poor physical and psychological employee health.

Workers are not immune from common mental health problems such as anxiety and depression. The prevalence of mental health problems among sickness benefit claimants is increasing with over 40 per cent of sickness claims recording a mental or behavioral disorder as a primary condition [13]. The business case for investing in worker wellbeing is well documented [14]. Poor worker wellbeing has a cost implication. For example, costs associated with reduced productivity/delays, reduced worker motivation and poor-quality work, staff retention, sick leave, errors, and poor customer service/customer retention. Unsurprisingly, many companies have introduced workplace Stress Management Initiatives' (SMI) and 'Workplace Wellbeing Programs' (WWP) programs [15]. Some wellness programs deploy corporate wellness self-tracking technologies (CWST) [16]. However, it has been argued that such technologies conflate work and health [17] and may exacerbate worker stress and/or anxiety [18].

\section{$3 \quad$ Research Project \& Methodology}

The 'Intelligent Work' project investigates how workers, automation, artificial intelligence technologies can collaborate in an efficient, intelligent, and humane way, to enhance worker wellbeing along with boosting the company's long-term revenue. The human factors approach involves building an evidence map in relation to the requirements for future work practices and the allied specification of new technologies to support this. The stakeholder evaluation approach involves the use of a community of practice [19] comprising both internal stakeholders (IS) and external stakeholders (ES). As defined in Table 1 below, this has involved eight phases of research. As each phase of research has progressed, the progressive findings have been triangulated, to further develop and validate the evidence map. The specific methodology combines traditional human factors action research methods (i.e., interviews and workshops), with participatory foresight activities, participatory co-design and evaluation activities, and data 
assessment. The study protocol was approved by the Ethics Committee of the School of Psychology, Trinity College Dublin.

Table 1. Overview of Research Stages

\begin{tabular}{|c|c|c|}
\hline \# & Method & Description of research and analysis \\
\hline 1 & $\begin{array}{l}\text { Existing product re- } \\
\text { view. }\end{array}$ & $\begin{array}{l}\text { Product demonstration and review (Work- } \\
\text { shop } 1, \mathrm{IS}, \mathrm{N}=4 \text { ). }\end{array}$ \\
\hline 2 & Preliminary human & HFEC Evaluation/IS (N=2) \\
\hline & $\begin{array}{l}\text { factors and ethics as- } \\
\text { sessment. }\end{array}$ & $\begin{array}{l}\text { Personae \& Scenarios Specification/IS } \\
(\mathrm{N}=2) .\end{array}$ \\
\hline 3 & $\begin{array}{l}\text { New Product Idea- } \\
\text { tion. }\end{array}$ & N/A. \\
\hline 4 & $\begin{array}{l}\text { Mapping the prob- } \\
\text { lem space \& further } \\
\text { specification/validation } \\
\text { of Concept \& Require- } \\
\text { ments. }\end{array}$ & $\begin{array}{l}\text { Interviews/IS }(\mathrm{N}=6) \text {. } \\
\text { Interview/ES }(\mathrm{N}=3) \text {. } \\
\text { Modelling IW Concept (Workshop 2, IS, } \\
\mathrm{N}=7 \text { ). Survey/ES }(\mathrm{N}=47) \text {. }\end{array}$ \\
\hline 5 & $\begin{array}{l}\text { Prototype } \\
\text { ment } \& \text { Develop- } \\
\text { views/Codesign. }\end{array}$ & $\begin{array}{l}\text { IW Concept Evaluation (Workshop 3, I, } \\
\mathrm{N}=7 \text { ). } \\
\text { Interviews \& Codesign with External Stake- } \\
\text { holders }(\mathrm{N}=15) \text {. }\end{array}$ \\
\hline 6 & $\begin{array}{l}\text { Operations Manage- } \\
\text { ment - Data Analysis. }\end{array}$ & Analysis of anonymous data set. \\
\hline 7 & $\begin{array}{l}\text { Implementation \& } \\
\text { Business Analysis. Fi- } \\
\text { nal Ethics Assessment. }\end{array}$ & $\begin{array}{l}\text { Using Data (Workshop 4, IS N=10). } \\
\text { Business Case (Workshop 5, IS N=10). } \\
\text { Implementation, Ethics \& Acceptability } \\
\text { (Workshop 6, IS, N=10). Final Specification \& } \\
\text { Implementation (Workshop 7/IS, N=10). }\end{array}$ \\
\hline 8 & $\begin{array}{l}\text { Final Analysis \& } \\
\text { Specification. }\end{array}$ & $\begin{array}{l}\text { Content Analysis (interviews - IS \& ES). } \\
\text { Final requirements specification. }\end{array}$ \\
\hline
\end{tabular}

\section{$4 \quad$ High Level Results \& Emerging Concept}

\subsection{Experience of Work \& Concepts of Healthy Work}

Survey findings indicate varied sources of WRS. Unclear processes present the biggest challenge $(11.65 \%)$ followed by long working hours $(9.71 \%)$. Three factors were rated third. These are pressure to meet deadlines, repetitive work. and the commute to work (all $7.77 \%$ ). $75 \%$ of survey respondents indicated that their company is interested in their wellbeing. All interview participants stated that their company was mostly interested in protecting employee wellbeing. Both survey and interview findings suggest that healthy work is defined in relation to management of workload, supporting positive team relations and communications, and the provision of autonomy and flexibility in work. 


\subsection{Intelligent Work: Concept \& Features}

Both survey and interview feedback highlight the requirement to advance a 'people centered operations concept' which prioritizes the human role, in an increasingly technology mediated work environment. The 'intelligent work' (IW) concept is characterized by an information access/availability approach - the ability to work from anywhere at any time. From an operational perspective, IW involves providing support for managing work/workload, the home/work interface, and sources of work-related stress (WRS), but not necessarily health monitoring in work. Both interview and survey feedback indicate that the focus should be on enabling/augmenting people as opposed to either work monitoring and/or health monitoring. Health in work relates to the transparent management of work and workload, being assigned the right work (i.e., matching competency/skills) and good communication across team members. This requires a strong emphasis on supporting teamwork. However, field research indicates that the person should be in control of how they obtain help from team members, team supervisors, and the system (including task assistants and robotic agents). Performance monitoring is a key issue. IW needs to be framed from the perspective of self-regulation. The person controls how information about their work and their work performance (i.e., through-put and work quality) is shared with others. Employees would like to obtain feedback to improve their own performance (self-regulation). Further, employees would like to benchmark their own performance against others.

\subsection{Role of Technology}

The person is allocated work based on smart allocation technology. This technology is predicated on (1) human factors best practice (i.e., model of relationship between work variety/complexity and engagement/performance), and (2) specific knowledge of the individual (i.e., abilities, experience, preferences, working hours and working styles). Importantly, work allocation follows a real-time model of specific worker competencies and experience levels. Also, it is based on a fair capacity/workload assignment (considering the workload of other team members and the business demand). Further, it is balanced to provide appropriate levels of work variety/diversity and complexity (i.e., the sweet spot for engagement and personal development). In addition to smart allocation, the proposed IW technology should provide task assistance to workers - to minimize the stress of looking for information and/or seeking help. Further, this technology might include robotic agents, who perform certain repetitive tasks and provide supports to human team members (for example, finishing tasks, monitoring team member needs, monitoring quality issues, and providing automated feedback to customers).

The worker provides real-time feedback about their performance both in relation to factors such as work suitability, work performance, worker engagement, and health in work. The system also provides the person with feedback about their own performance, so that the worker can assess themselves and manage their own performance - and alert the supervisor if help/intervention is required. Equally, the supervisor has access to this information, so that they can 'coach' the worker. Participants highlighted that performance information should be carefully protected, with clear rules as to how the 
supervisor or other managers might use this information. Further it was suggested that the introduction of performance feedback should happen gradually - starting with individual feedback. Once this new approach has been accepted and adopted, it might be possible to provide team level feedback, to support self-regulating teams.

\subsection{Structuring Framework \& Measuring}

As reported by interview participants, 'what gets measured gets done'. Thus, is it necessary to select the right performance targets at different levels (i.e., work, individual, team etc). To this end, performance assessment and feedback needs to reflect a 'contract concept', informed by concepts of accountability. Data and intelligence can be used to generate leading indicators for business success along with employee health. Figure 1 provides an overview of relevant evaluation metrics linked to this. This contract concept contributes to a 'balance score card', to access organizational performance across the triple bottom line.

\begin{tabular}{|c|c|c|c|}
\hline \multicolumn{4}{|l|}{ Click to add text } \\
\hline RRGANISATION & WORK \& BUSINESS PROCESS & WORKER LEVEL & CUSTOMER LEVEL \\
\hline Profit and turnover & - Productivity & - Wellbeing in work & - No of customers \\
\hline Productivity & - Efficiency & -Workload & - Growth - no of new \\
\hline Efficiency & Quality of work produced & $\begin{array}{l}\text { - Fatigue } \\
\text { - Burnout }\end{array}$ & customers \\
\hline $\begin{array}{l}\text { Regulatory compliance (costs } \\
\text { of breaches) }\end{array}$ & - Teamwork and social & - Engagement/motivation & $\begin{array}{l}\text { - Customer attrition } \\
\text { - Satisfaction }\end{array}$ \\
\hline Quality of work produced & cohesion & $\begin{array}{l}\text { - Professional fulfilment } \\
\text { - Psychological wellbeing in }\end{array}$ & - Perception of brand \\
\hline $\begin{array}{l}\text { Health performance } \\
\text { - Absenteeism (cost of sick } \\
\text { leave) } \\
\text { - Staff retention (cost of } \\
\text { training) }\end{array}$ & & $\begin{array}{l}\text { work } \\
\text { - Trust } \\
\text { - Job satisfaction } \\
\text { - Errors }\end{array}$ & \\
\hline $\begin{array}{l}\text { Accident/Errors/Malpractice } \\
\text { (\& Costs) }\end{array}$ & & - Accidents & \\
\hline
\end{tabular}

Fig. 1. Performance Levels, Success Criteria \& Outcomes

\section{Discussion}

Workplace stress and psychosocial risk is an organizational issue which should be addressed in relation to the introduction of smart work management systems. Automation, AI \& ML technologies can be used to capture and analyze data pertaining to the relationship between work, human performance and health, customer outcomes and organizational outcomes. This will ensure that employee health protection and promotion is an outcome of work management. The introduction of these technologies will be underpinned by positive change in relation to supporting wellbeing culture in financial services, and the integration of previously diverse processes and functions pertaining to business process management, customer management, human resources, occupational health and safety/health protection, and health promotion.

Future work technology will enable 'intelligent work' through the application of AI/ML, which enables healthy work allocation and monitoring - balancing different perspectives and needs - the work, the person, the team, the customer, and business 
value. Intelligent assistants function as supportive team members - augmenting and transforming all roles, including team members, supervisors, operations managers, and the customer. Critically, the system supports 'coaching' of team members and worker self-regulation and self-management.

Healthy work underpins intelligent work. Healthy work can be defined in relation to several features - (1) knowing the person (identity, motivations/goals, skills, preferences, working styles, cases worked on, team experience and achievements), (2) focusing on flow and work performance (i.e., workload balancing, type of work, flexibility, communications, feedback), (3) fostering autonomy and self-management, (4) ensuring the people are part of a team and have a purpose and (5) developing people's strengths. As such, it is more aligned with concepts of workforce monitoring, as opposed to health monitoring.

Intelligent work involves understanding the performance of an organization through the lens of multiple stakeholders. Stakeholders have divergent goals and are rewarded differently. This requires rethinking the organization's mission and purpose and the role of people in supporting this (i.e., focus on human needs and outcomes). For this to happen, there needs to be a shared understanding of the relationship between business objectives and how work is managed, the requirements for healthy work, along with common goals and trust. There are roles and responsibilities on different sides (i.e., individual, team, automation, and organization). The 'contract' is embedded in the 'socio-technical' system and requires elaboration in relation to process definition, training, tools design and culture. Evidently, the implementation of the 'contract' will vary according to the organization's culture and technology capacity.

Some limitations should be noted. Observational research at financial services companies was planned, but not possible during the COVID 19 pandemic. The numbers in each of the three phases of combined interviews and co-design/evaluations were small $(\mathrm{N}=5$ in each phase, total: $\mathrm{N}=15)$. Further, a small number of participant's completed the survey $(\mathrm{N}=47)$. Limited feedback was obtained from team members. The operations management dataset reflected work activity that was managed without a formal work allocation/process management software. The next phase of research will involve deep human factors research and potential implementation, with an organization, involving the participation of different operational roles, the customer, and the regulator.

\subsection{Conclusion}

New intelligent work technologies should support enable work that is smart, healthy, and ethical. This involves moving beyond simply process automation and the use of robotic team members. Technologies should augment all human actors, promote teamwork behaviors, and ensure that human actors can self-manage and monitor their own performance. This new concept of 'intelligent work' and 'self-monitoring employees' is underpinned by automation and AI technologies, which deliver on an 'intelligent contract'. There is a strong human/moral imperative along with a business case to move towards 'intelligent work' concepts. Healthy work concepts need to be embedded in how work is planned/allocated, carried out, monitored, and evaluated/assessed, linking to workplace health protection and promotion processes. 


\section{References}

1. Elkington, John. Cannibals with forks: the triple bottom line of 21 st century business. Oxford: Capstone. ISBN 9780865713925. OCLC 963459936 (1999).

2. Conaway, R. N., \& Laasch, O. Communication in Responsible Business: Strategies, Concepts, and Cases. 2012. Business Expert Press.

3. Sengenberger, W. The international labour organization: goals, functions, and political impact. Friedrich Ebert Stiftung, Berlin. 2013.

4. International Labour Organisation (ILO). Tripartite Conculation. Available at: https://www.ilo.org/global/standards/subjects-covered-by-international-labour-standards/tripartite-consultation/lang--en/index.htm

5. Cooper, R., Lean enterprises and the confrontation strategy. Academy of Management Perspectives, 10(3), pp.28-39, 1996.

6. Centre for Disease Control and Prevention (CDC). Workplace Health Model. Available from: https://www.cdc.gov/workplacehealthpromotion/model/

7. The World Health Organisation (WHO). Healthy workplace model. Available at: https://www.who.int/occupational_health/healthy_workplace_framework.pdf

8. International Standards Organisation (ISO). ISO/FDIS 45003. Occupational health and safety management - Psychological health and safety at work - Guidelines for managing psychosocial risks. Available from: https://www.iso.org/standard/64283.html

9. International Standards Organisation (ISO). ISO/PAS 45005:2020

Occupational health and safety management - General guidelines for safe working during the COVID-19 pandemic. Available from https://www.iso.org/standard/64286.html

10. Hackman, J.R. and Oldham, G.R. "Motivation through the design of work: test of a theory", Organizational Behavior and Human Performance, Vol. 16 No. 2, pp. 250-279. 1976.

11. Ragu-Nathan, T. S., Tarafdar, M., Ragu-Nathan, B. S., \& Tu, Q. The consequences of technostress for end users in organizations: Conceptual development and empirical validation. Information Systems Research, 19(4), 417-433, 2008.

12. Barber LK, Santuzzi AM. Please respond ASAP: workplace telepressure and employee recovery. J Occup Health Psychol. 2015 Apr;20(2):172-89. doi: 10.1037/a0038278. Epub 2014 Nov 3. PMID: 25365629.

13. Judith Brown, Phil Hanlon, Ivan Turok, David Webster, James Arnott, Ewan B. Macdonald, Mental health as a reason for claiming incapacity benefit - a comparison of national and local trends, Journal of Public Health, Volume 31, Issue 1, March 2009, Pages 74-80.

14. Bevan S (2010) The business case for employee health and wellbeing: A report prepared for investors in people UK. Available at: http://workfoundation.org/assets/docs/publications/245_iip270410.pdf

15. Tetrick, Lois and Winslow, Carolyn, Workplace Stress Management Interventions and Health Promotion. Annual Review of Organizational Psychology and Organizational Behavior, Vol. 2, Issue 1, pp. 583-603, 2015.

16. Till C, Petersen A, Tanner C, Munsie M. Creating "automatic subjects": Corporate wellness and self-tracking. Health: An Interdisciplinary Journal for the Social Study of Health, Illness \& Medicine. 2019;23(4):418.

17. Hull, G. \& Pasquale, F. Toward a critical theory of corporate wellness. BioSocieties 13(1): 190-212. 2018.

18. Moore, $P$ \& Robinson, A. The quantified self: What counts in the neoliberal workplace. New Media \& Society 18(11): 2774-2792. 2016.

19. Wenger, E. Communities of Practice: Learning, Meaning, and Identity; Cambridge University Press: Cambridge, UK (1998). 